CLINICAL STUDY

\title{
Low prevalence of the metabolic syndrome but high occurrence of various metabolic disorders in Chinese women with polycystic ovary syndrome
}

\author{
Ren-min $\mathrm{Ni}^{1,2}$, Yaqin $\mathrm{Mo}^{1}$, Xiaoli Chen ${ }^{1}$, Junmin Zhong ${ }^{1}$, Wen Liu and Dongzi Yang ${ }^{1}$ \\ ${ }^{1}$ Department of Obstetrics and Gynecology, The Second Affiliated Hospital, Sun Yat-Sen University, No. 107, Yanjiang Road, Guangzhou, Guangdong \\ 510120, People's Republic of China and ${ }^{2}$ Department of Obstetrics and Gynecology, The First Affiliated Hosiptal of Kunming Medical College, No. 295 , \\ Xichang Road, Kunming, Yunnan 650032, People's Republic of China \\ (Correspondence should be addressed to D Yang; Email: yangdz@mail.sysu.edu.cn)
}

\begin{abstract}
Objective: Variations in the prevalence of metabolic syndrome (MetS) among women with polycystic ovary syndrome (PCOS) in different races were reported. We sought to report this prevalence and its components in Chinese women with PCOS and compared these characteristics with healthy controls. Design: Anthropometric measurements and biochemical parameters were evaluated in 578 PCOS patients diagnosed by the Rotterdam criteria and 281 age- and body mass index (BMI)-matched controls. International Diabetes Federation criteria for MetS were used.

Results: The prevalence of MetS was $16.8 \%$ in this study, and $60.7 \%$ of patients displayed at least one component of MetS. Among the patients, the rates of dyslipidemia, impaired fasting glucose, and elevated blood pressure were $41.6,19.8$, and $16.1 \%$ respectively; the rates of these corresponding components in age- and BMI-matched controls were 14.6, 5.3, and 5.7\% respectively. In PCOS patients, the prevalence of MetS was 0.0, 3.9, 20.2, and 51.1\% for four different BMI groups respectively; the prevalence of MetS was 7.3, 14.9, 24.2, and $42.4 \%$ in the four age groups respectively. Nearly $90 \%$ of patients diagnosed with MetS belonged to overweight and obese groups. BMI and age rather than free testosterone, free androgen index, fasting insulin, or sex hormone-binding globulin were included in formulation for predicting MetS according to multivariable logistic regression. Conclusions: Low prevalence of MetS but high occurrence of various metabolic disorders was found in women with PCOS compared with age- and BMI-matched controls in this study. BMI and age appeared to contribute more to developing MetS than other parameters associated with insulin resistance or hyperandrogenism.
\end{abstract}

European Journal of Endocrinology $161411-418$

\section{Introduction}

Metabolic syndrome (MetS) is characterized by metabolic abnormalities that place individuals at increased risk of cardiovascular diseases (CVD). These metabolic abnormalities include the following: diabetes and raised fasting plasma glucose; abdominal obesity; dyslipidemia; and high blood pressure $(1,2)$. These risk factors lead to increased morbidity and mortality due to atherosclerotic disease, kidney disease, and increased risk of stroke. Moreover, there is now strong epidemiological evidence that indicates a link between MetS and several cancers, including colon and breast cancer (3-5). Evidence has shown that insulin resistance (IR) and compensatory hyperinsulinemia play central roles in the pathophysiology of MetS.

Polycystic ovary syndrome (PCOS) is regarded as one of the most common endocrine diseases among women of childbearing age, affecting from 5 to $10 \%$ of women in this age range (6-8). Patients with PCOS often have complications associated with dyslipidemia, diabetes mellitus/impaired glucose tolerance, and hypertension, and are therefore at increased risk of having MetS (8-10). The prevalence of MetS in PCOS patients varies among different ethnicities and has been reported to be 43.0-47.3\% in America (11-13), 46.2\% in India (14), 28.4\% in Brazil (15), 14.5\% in Korea (16), and $35.3 \%$ in Thailand (17).

Given the variations reported in the prevalence of MetS among PCOS patients of different races and the paucity of literature describing the prevalence of metabolic disorders including MetS in PCOS patients in mainland China, we sought to report these characteristics and compared them to healthy controls. 


\section{Materials and methods}

\section{Patients and control subjects}

A total of 974 adult PCOS patients (20-41 years of age) were diagnosed consecutively at the Department of Gynecology and Reproductive Center of the Second Affiliated Hospital of Sun Yat-Sen University from January 2004 to October 2008. Patients' records were reviewed and 578 patients with adequate data, specifically physical examination data, and sufficient laboratory blood tests to diagnose MetS were included in the study. Age- and body mass index (BMI)-matched controls comprised 281 women recruited randomly from an annual routine physical examination (18). All controls were clinically healthy and were euthyroid according to clinical evaluation and thyroid-stimulating hormone (TSH) measurement. The study was approved by the institutional review board of the Second Affiliated Hospital of Sun Yat-Sen University.

PCOS patients were diagnosed according to the Rotterdam criteria (19), meeting at least two out of the following three criteria: i) oligo- and/or anovulation (i.e. $\leq 8$ menstrual periods in a year or menstrual cycles more than 35 days in length) (20), ii) clinical hyperandrogenism (i.e. acne or modified FerrimanGallwey scores $\geq 8$ (21)) or biochemical hyperandrogenism (i.e. serum total testosterone (TT) $>2.6 \mathrm{nmol} / \mathrm{l}$, free testosterone (FT) $\geq 6.0 \mathrm{pg} / \mathrm{ml}$, testosterone and FT normal values were determined by the clinical laboratory of the gynecology department at the Second Affiliated Hospital of Sun Yat-Sen University), and iii) ultrasonographic findings of ovarian polycystic morphology (i.e. presence of $\geq 12$ follicles in each ovary measuring $2-9 \mathrm{~mm}$ in diameter) and exclusion of related disorders such as hypothyroidism, hyperprolactinemia, and adrenal hyperplasia by physical examination and lab testing of TSH, prolactin (PRL), and serum $17 \alpha$-hydroxyprogesterone (17 $\alpha$-OHP).

Patients were defined as having MetS, based on International Diabetes Federation (IDF) criteria for MetS (22), if they had central obesity (waist circumference $\geq 80 \mathrm{~cm}$ ) plus two or more of the following four factors: i) increased concentration of triglycerides (TG): $\geq 1.7 \mathrm{mmol} / \mathrm{l}$, ii) reduced concentration of high-density lipoprotein cholesterol (HDL-C): $<1.29 \mathrm{mmol} / \mathrm{l}$, iii) raised blood pressure: systolic pressure $\geq 130 \mathrm{mmHg}$ or diastolic pressure $\geq 85 \mathrm{mmHg}$ or treatment of previously diagnosed hypertension, and iv) increased fasting glucose (FG) level $\geq 5.6 \mathrm{mmol} / \mathrm{l}$ (impaired FG, IFG) or previously diagnosed type 2 diabetes.

\section{Study protocol}

All PCOS patients underwent anthropometric measurements, including weight, height, waist and hip circumferences, blood pressure, modified FerrimanGallwey scores, and acne scores. Ferriman-Gallwey scores were assessed by at least two observers. Control subjects received the same anthropometric measurements with the exception of waist and hip circumferences.

Body weight, height, and waist and hip circumferences were measured based on methods recommended by the World Health Organisation (23). BMI was calculated as weight $(\mathrm{kg}) /$ height $\left(\mathrm{m}^{2}\right)$. Underweight was defined as a BMI $<18.5$, normal weight as a $\mathrm{BMI} \geq 18.5$ and $<23.0$, overweight as a $\mathrm{BMI} \geq 23.0$ and $<25.0$, and obesity as a BMI $\geq 25$, according to the Asia-Pacific criteria of BMI for obesity (24).

Fasting blood samples were obtained from PCOS patients between the first and fifth day of the menstrual period/withdrawal bleed in order to measure PRL, LH, $\mathrm{FSH}$, estradiol $\left(\mathrm{E}_{2}\right)$, and TT by the chemiluminescence immunoassays Access 2 (Beckman, Fullerton, California, USA); FT, sex hormone-binding globulin (SHBG), DHEAS, and 17-OHP were measured by Access 2 ELISAs (Beckman). TSH was measured using a chemiluminescence immunometric assay (Immulite 2000 Analyzer; CPC, Los Angeles, CA, USA). The free androgen index (FAI), a parameter of bioavailable testosterone, was calculated from TT and SHBG as follows: $\mathrm{FAI}=(\mathrm{TT}(\mathrm{nmol} / \mathrm{l}) \times 100 / \mathrm{SHBG}(\mathrm{nmol} / \mathrm{l}))(25)$. Fasting venous blood samples were also used to measure the levels of glucose, insulin, total cholesterol (CHOL), HDL-C, and TG. Plasma glucose was measured by the glucose oxidase method (Hitachi 7600) and plasma insulin was measured using a chemiluminescence immunometric assay and commercial kit (Immulite 2000 Analyzer; CPC). CHOL, HDL-C, and TG were measured using an enzymatic calorimetric method with the 7600 autoanalyzer (Hitachi 7600). Homeostasis model assessment (HOMA) was applied to estimate the degree of IR. The equation used to obtain this value is as follows: HOMA-IR $=$ (fasting plasma glucose $(\mathrm{mmol} / \mathrm{l})$ $\times$ insulin $(\mu \mathrm{U} / \mathrm{ml})) / 22.5(26)$.

For controls, fasting blood samples were collected and the same methodologies described above were used to measure TT, FT, SHBG, DHEAS, 17-OHP, PRL, TSH, fasting insulin (FI), FG, TG, and CHOL. HOMA-IR was also calculated.

\section{Statistical analyses}

The data were analyzed using the statistical software SPSS version 13.0 for Windows (SPSS, Inc., Chicago, IL, USA). We assessed the normality of the distribution of all continuous variables using the KolmogorovSmirnov test. Because the data were not normally distributed, continuous variables were presented as median values with an interquartile range (25-75th percentile), and differences in medians between groups were determined by the Mann-Whitney test. For the categorical variables, Pearson $\chi^{2}$ test was used to analyze the differences between groups and to obtain an odds ratio (OR). Logistic regression analyses were 
employed to determine risk factors for MetS and to estimate the ORs for MetS. The Wald $\chi^{2}$ test was used to test the logistic regression model. Statistical significance was set at $P<0.05$.

\section{Results}

\section{Clinical and metabolic features of patients and controls}

Of the sample with PCOS, 94.3\% $(n=545)$ were 35 years of age or younger. A large number of women in this sample presented oligomenorrhea or amenorrhea (84.3\%), ultrasonographic appearance of polycystic ovaries $(91.4 \%)$, and clinical hyperandrogenism or biochemical hyperandrogenism $(78.4 \%)$. None of the 578 PCOS patients were previously diagnosed with type 2 diabetes.

The comparison of clinical and metabolic features between PCOS patients and age- and BMI-matched healthy controls was summarized (Table 1). PCOS patients demonstrated increased systolic blood pressure, diastolic blood pressure, FG, FI, HOMA-IR, TT, DHEAs, TG, and CHOL. However, there was no statistically significant difference in terms of the level of FT, SHBG, and FAI between age- and BMI-matched controls and PCOS patients.

Among the women with PCOS, those who met the criteria for MetS displayed significantly higher mean age, waist circumference, BMI, waist circumference to hip, FT, FAI, HOMA-IR, FG, FI, TG, and lower SHBG, LH, and HDL-C levels than patients who did not meet the criteria for MetS. No significant differences in the levels of FSH, $\mathrm{E}_{2}$, TT, and DHEAS were detected between PCOS patients with MetS and those without MetS (Table 2).

\section{Prevalence of MetS and metabolic features}

The prevalence of MetS was $16.8 \%$, based on IDF criteria, in the present cohort of women with PCOS. The rate of dyslipidemia (higher TG or CHOL), IFG, and increased blood pressure was significantly higher in women with PCOS than that in the age- and BMImatched control group (Fig. 1). In this sample of PCOS patients, dyslipidemia was the most common metabolic feature $(41.6 \%)$, and the next most common one was overweight or obesity (38.4\%). A smaller portion of patients with PCOS presented IFG (19.8\%) and elevated blood pressure (16.1\%). Generally, the rates of the above-mentioned metabolic disorders in PCOS patients increased over two times when compared with the ageand BMI-matched controls.

Of the 578 PCOS patients, $60.7 \%(n=351)$ had one component of MetS; $33.3 \%(n=191)$ had two components; $17.6 \%(n=102)$ had three components; $5.5 \%$ $(n=32)$ had four components; and only $1.4 \%(n=8)$ had all five components.

\section{Prevalence of MetS in different BMI and age subgroups}

We classified women with PCOS into four BMI groups and the prevalence of MetS increased with BMI (Table 3). The prevalence increased gradually from $3.9 \%$ in the normal weight group to $51.1 \%$ in the obese group $(P<0.0001)$. The risk of having MetS increased nearly fivefold in the overweight group when compared with the normal weight group, threefold in the obese group when compared with the overweight group, and 25-fold in the obese group when compared with the normal weight group. Of the PCOS patients with MetS

Table 1 Comparison of clinical and biochemical parameters of polycystic ovary syndrome (PCOS) patients and the age- and body mass index-matched controls.

\begin{tabular}{|c|c|c|c|}
\hline Variables & Age- and BMI-matched controls & Pcos & $P$ value \\
\hline$n$ & 281 & 578 & - \\
\hline Age (years) & $28.0(26.0-31.0)$ & $27.0(25.0-30.0)$ & $>0.05$ \\
\hline $\mathrm{BMI}\left(\mathrm{kg} / \mathrm{m}^{2}\right)$ & $21.9(20.9-23.8)$ & $21.9(19.7-24.8)$ & $>0.5$ \\
\hline $\mathrm{SBP}(\mathrm{mmHg})$ & $106.0(99.0-113.0)$ & $110.9(100.0-120.0)$ & $<0.001$ \\
\hline $\mathrm{DBP}(\mathrm{mmHg})$ & $69.0(62.0-74.0)$ & $73.0(66.0-80.0)$ & $<0.001$ \\
\hline Testosterone $(\mathrm{nmol} / \mathrm{l})$ & $1.8(1.5-2.2)$ & $2.3(1.6-2.9)$ & $<0.001$ \\
\hline $\mathrm{FT}(\mathrm{pmol} / \mathrm{l})$ & 146.9 (72.9-168.8) & $156.2(69.4-177.0)$ & $>0.05$ \\
\hline $\mathrm{FAl}$ & $4.1(2.3-6.0)$ & $4.4(2.4-7.5)$ & $>0.1$ \\
\hline DHEAS $(\mu \mathrm{mol} / \mathrm{l})$ & $4.4(3.2-5.7)$ & $5.3(3.8-7.1)$ & $<0.001$ \\
\hline $\mathrm{SHBG}(\mathrm{nmol} / \mathrm{l})$ & $57.6(29.9-85.83)$ & $51.0(31.3-82.8)$ & $>0.5$ \\
\hline 17-OHP $(\mu \mathrm{mol} / \mathrm{l})$ & $3.5(1.5-4.0)$ & $3.6(1.8-4.5)$ & $>0.5$ \\
\hline TSH (mIU/l) & $2.5(1.3-4.1)$ & $2.5(1.5-3.8)$ & $>0.5$ \\
\hline $\mathrm{TG}(\mathrm{mmol} / \mathrm{l})$ & $0.8(0.6-1.2)$ & $1.1(0.8-1.7)$ & $<0.001$ \\
\hline $\mathrm{CHOL}(\mathrm{mmol} / \mathrm{l})$ & $4.6(4.1-5.1)$ & $5.0(4.3-5.7)$ & $<0.001$ \\
\hline $\mathrm{FG}(\mathrm{mmol} / \mathrm{l})$ & $4.7(4.4-5.0)$ & $5.0(4.7-5.3)$ & $<0.001$ \\
\hline $\mathrm{FI}(\mu \mathrm{U} / \mathrm{ml})$ & $4.9(3.3-7.0)$ & $7.5(4.6-12.0)$ & $<0.001$ \\
\hline HOMA-IR & $1.0(0.7-1.6)$ & $1.7(1.0-2.7)$ & $<0.001$ \\
\hline
\end{tabular}

Variables were expressed as median with (25-75th percentile). BMI, body mass index; SBP, systolic blood pressure; DBP, diastolic blood pressure; Testosterone, total testosterone; FT, free testosterone; FAI, free androgen index $=(\mathrm{T} \times 100) / \mathrm{SHBG}$; SHBG, sex hormone-binding globulin; 17-OHP, 17-hydroxyprogesterone; TG, triglycerides; CHOL, total cholesterol; FG, fasting glucose; FI, fasting insulin; HOMA-IR, homeostasis model assessment of insulin resistance. 
Table 2 Comparison of clinical and biochemical parameters of polycystic ovary syndrome (PCOS) patients with and without the metabolic syndrome (MetS).

\begin{tabular}{|c|c|c|c|}
\hline Variables & Women with MetS & Women without MetS & $P$ value \\
\hline$n$ & 97 & 481 & - \\
\hline Age (years) & $29.0(27.0-32.0)$ & $27.0(25.0-29.0)$ & $<0.0001$ \\
\hline Body weight (kg) & $66.5(60.5-75.0)$ & $52.0(48.0-59.0)$ & $<0.0001$ \\
\hline BMI $\left(\mathrm{kg} / \mathrm{m}^{2}\right)$ & $26.7(24.6-29.5)$ & $21.1(19.3-23.4)$ & $<0.0001$ \\
\hline WC $(\mathrm{cm})$ & $88.0(83.5-94.3)$ & $73.5(69.0-80.0)$ & $<0.0001$ \\
\hline WHR & $0.92(0.88-0.95)$ & $0.83(0.79-0.87)$ & $<0.0001$ \\
\hline $\mathrm{SBP}(\mathrm{mmHg})$ & $120.0(110.0-130.0)$ & $110.0(100.0-120.0)$ & $<0.0001$ \\
\hline $\mathrm{DBP}(\mathrm{mmHg})$ & $80.0(70.0-90.0)$ & $70.0(65.0-80.0)$ & $<0.0001$ \\
\hline FSH (IU/I) & $6.1(4.8-7.6)$ & $6.5(5.3-7.9)$ & $>0.05$ \\
\hline LH (IU/I) & $7.7(4.9-11.1)$ & $9.4(5.0-15.1)$ & $>0.05$ \\
\hline $\mathrm{E}_{2}(\mathrm{pmol} / \mathrm{l})$ & $198.2(133.6-309.0)$ & $189.4(124.1-292.9)$ & $>0.05$ \\
\hline Testosterone $(\mathrm{nmol} / \mathrm{l})$ & $2.1(1.5-2.6)$ & $2.2(1.7-2.9)$ & $>0.05$ \\
\hline $\mathrm{FT}(\mathrm{pmol} / \mathrm{l})$ & $152.7(111.0-242.9)$ & $111.1(69.4-166.6)$ & $<0.0001$ \\
\hline FAI & $7.7(4.0-16.1)$ & $3.9(2.2-6.9)$ & $<0.0001$ \\
\hline DHEAS $(\mu \mathrm{mol} / \mathrm{l})$ & $5.3(3.9-6.7)$ & $5.3(3.8-7.2)$ & $>0.05$ \\
\hline SHBG $(\mathrm{nmol} / \mathrm{l})$ & 27.8 (15.6-50.2) & $55.4(35.4-87.6)$ & $<0.0001$ \\
\hline $\mathrm{TG}(\mathrm{mmol} / \mathrm{l})$ & $2.2(1.8-3.0)$ & $1.0(0.7-1.3)$ & $<0.0001$ \\
\hline HDL-C (mmol/l) & $1.2(1.0-1.3)$ & $1.6(1.4-1.9)$ & $<0.0001$ \\
\hline $\mathrm{FG}(\mathrm{mmol} / \mathrm{l})$ & $5.4(5.0-6.0)$ & $5.0(4.7-5.3)$ & $<0.0001$ \\
\hline $\mathrm{FI}(\mu \mathrm{U} / \mathrm{ml})$ & $13.6(9.9-19.9)$ & $6.7(4.1-10.1)$ & $<0.0001$ \\
\hline HOMA-IR & $3.3(2.4-4.5)$ & $1.5(0.9-2.3)$ & $<0.0001$ \\
\hline
\end{tabular}

Variables were expressed as median with 25-75th percentile. BMI, body mass index; WC, waist circumference; WHR, waist circumference to hip circumference ratio; SBP, systolic blood pressure; DBP, diastolic blood pressure; Testosterone, total testosterone; FT, free testosterone; FAI, free androgen index $=(T \times 100) / S H B G$; SHBG, sex hormone-binding globulin; 17-OHP, 17-hydroxyprogesterone; TG, triglycerides; HDL-C, high-density lipoprotein cholesterol; FG, fasting glucose; HOMA-IR, homeostasis model assessment of insulin resistance.

$(n=97), 88.7 \%(n=86)$ were overweight and obese, and $11.3 \%(n=11)$ were of normal weight.

The PCOS patients were divided into four age groups and the prevalence of MetS for four age groups was presented in Table 3. The risk of having MetS in the older group ( $\geq 35$ years) was nine times higher than that in the younger group (20-24 years; $P<0.0001)$. When these PCOS patients were divided into three age groups ( $<30$ years, 30-39 years, $\geq 40$ years), the prevalence of MetS was $12.7 \%$ (54/425), 26.8\% $(40 / 149)$, and $75.0 \%(3 / 4)(P<0.001)$ respectively. This indicated that the prevalence of MetS increased with age.

\section{Predicting factors for MetS by multivariables regression analysis}

Because of the statistically significant differences in variables of age, BMI, SHBG, FT, FAI, LH, and FI between PCOS patients with MetS and without MetS $(P<0.0001)$, multivariables logistic regression analyses were performed to estimate the OR of the MetS using these variables as covariables, and the presence of MetS as the dependent variable. Two multiple logistic regression models were run using the same covariates, with the inclusion or absence of age (Table 4). All covariables were considered to be continuous variables. In the first model, only BMI $(P<0.001)$ was included in the equation and the OR was 1.451 (95\% confidence interval, CI, 1.298-1.622). After adjusting for age in model 2, the OR for BMI barely changed (1.413; 95\% CI,
1.259-1.586); furthermore, only age and BMI were included in the second model, and the OR for age was 1.134 (95\% CI, 1.044-1.231; $P=0.003$ ).

\section{Discussion}

In this study, the prevalence of MetS, as diagnosed according to IDF criteria, was $16.8 \%$ in the studied Chinese PCOS patients. Metabolic disorders were common in these Chinese women as more than half of

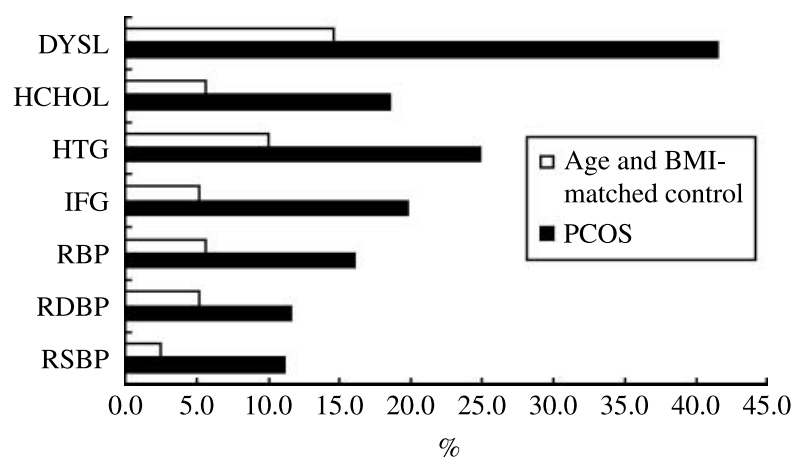

Figure 1 Metabolic disorders in PCOS and age- and BMI-matched controls. DYSL, dyslipidemia (high TG or high $\mathrm{CHOL}$ ); $\mathrm{HCHOL}$, high cholesterol; HTG, high triglycerides; IFG, impaired fasting glucose (fasting glucose $\geq 5.6 \mathrm{mmol} / \mathrm{l}$ ); RSBP, raised systolic blood pressure; RDBP, raised diastolic blood pressure; RBP, RSBP and/or RDBP. The difference of metabolic disorders was statistically significant between PCOS patients and the age- and BMI-matched controls $\left(P<0.0001\right.$, Pearson $\chi^{2}$ test). 
Table 3 Prevalence of the metabolic syndrome defined by International Diabetes Federation criteria among different age and body mass index groups in women with polycystic ovary syndrome (PCOS).

\begin{tabular}{|c|c|c|c|c|}
\hline Variables & $\operatorname{Pcos}(n)$ & PCOS with MetS & Prevalence of MetS (\%) & OR $(95 \% \mathrm{Cl})$ \\
\hline \multicolumn{5}{|l|}{ Age (years) } \\
\hline Group $1(\geq 20$ and $<25)$ & 123 & 9 & 7.3 & $9.3(3.5-24.6)^{\mathrm{a}}$ \\
\hline Group $2(\geq 25$ and $<30)$ & 302 & 45 & 14.9 & $2.2(1.1-4.7)^{b}$ \\
\hline Group $3(\geq 30$ and $<35)$ & 120 & 29 & 24.2 & $1.8(1.1-3.1)^{\mathrm{C}}$ \\
\hline Group $4(\geq 35)$ & 33 & 14 & 42.4 & $2.3(1.0-5.2)^{d}$ \\
\hline \multicolumn{5}{|l|}{ BMI $\left(\mathrm{kg} / \mathrm{m}^{2}\right)$} \\
\hline Underweight & 74 & 0 & 0 & - \\
\hline Normal weight & 282 & 11 & 3.9 & $6.3(2.8-13.8)^{\mathrm{e}}$ \\
\hline Overweight & 89 & 18 & 20.2 & $4.1(2.2-7.7)^{f^{\prime}}$ \\
\hline Obesity & 133 & 68 & 51.1 & $25.8(12.9-51.5)^{\mathrm{g}}$ \\
\hline
\end{tabular}

$\mathrm{BMI}$, body mass index; Underweight, $\mathrm{BMI}<18.5$; Normal weight, $\mathrm{BMI} \geq 18.5$ and $<23$; Overweight, $\mathrm{BMI} \geq 23$ and $<25$; Obesity, $\mathrm{BMI} \geq 25$.

${ }^{\mathrm{a} O R}(95 \% \mathrm{Cl})$, group 4 versus group $1(P<0.0001)$.

${ }^{\text {b } O R ~}(95 \% \mathrm{Cl})$, group 2 versus group $1(P<0.05)$.

${ }^{\mathrm{C}} \mathrm{OR}(95 \% \mathrm{Cl})$, group 3 versus group $2(P<0.05)$

${ }^{\mathrm{d}}$ OR $(95 \% \mathrm{Cl})$, group 4 versus group $3(P<0.05)$.

${ }^{\mathrm{e}} \mathrm{OR}(95 \% \mathrm{Cl})$, overweight versus normal weight group $(P<0.0001)$.

${ }^{\dagger} \mathrm{OR}(95 \% \mathrm{Cl})$, obesity versus overweight group $(P<0.0001)$.

${ }^{\mathrm{g} O R}(95 \% \mathrm{Cl})$, obesity versus normal weight group $(P<0.0001)$.

them (60.7\%) exhibited at least one component of MetS. Dyslipidemia and obesity were the two most common metabolic features. The rates of IFG and raised blood pressure were relatively low, but they were over three times as high as observed in age- and BMI-matched controls. This suggested that the risk of having metabolic disorders was significantly higher in PCOS patients compared with age- and BMI-matched controls.

Apart from the impact of different criteria for MetS used $(27,28)$, the prevalence of MetS detected in our population of PCOS patients differed from the results that have been documented for other ethnicities and nationalities, and this to some extent might be due to different genetics and lifestyles or dietary structures (29, 30). The prevalence of MetS was 43.0-47.3\% in USA $(8,9,11)$ by NCEP-ATP III criteria. Even based on the same IDF criteria, the prevalence of MetS still differed between ethnicities, with $33.8 \%$ in Germany (31), $40.0 \%$ in Australia (27), $46.2 \%$ in India (14), and $35.3 \%$ in Thailand (17). In the case of Thailand, the prevalence of MetS was $22.5 \%, 27.8 \%$, and $53.5 \%$ in three age groups $(<25, \geq 25$ and $<30, \geq 30$ years $)$ respectively, which was higher than those observed in similar age groups in our study. In Taiwan, the prevalence of MetS in PCOS patients based on IDF criteria was $16.0 \%$ (16/107) (32), similar to our results. Another factor, which contributed to the lower prevalence of MetS in our population of PCOS patients, was BMI. The BMI values in the Chinese PCOS patients were usually lower and central obesity less popular than other ethnicities $(30,33-35)$, whereas central obesity is one of the main contributors to developing the MetS. In our study, mean BMI was also lower than those in America, Germany, Australia, India, and Thailand. In addition, the size of studied sample may have had an effect on the difference of the prevalence of MetS.

The prevalence of MetS increased with BMI in the present study. After adjustment by age, the increasing trend in this prevalence remained. Among the underweight group, none suffered from MetS. Nearly $90 \%$ of PCOS patients with MetS belonged to overweight or

Table 4 Adjusted odds ratios (ORs) for metabolic syndrome in multivariable logistic regression analyses.

\begin{tabular}{|c|c|c|c|c|c|}
\hline Model & Covariables & Coefficient (B) & OR $(\operatorname{Exp}(\mathrm{B}))(95 \% \mathrm{Cl})$ & Wald $\left(\chi^{2}\right)$ & $P$ value \\
\hline \multirow[t]{6}{*}{1} & BMI & 0.372 & $1.451(1.298-1.622)$ & 42.802 & 0.000 \\
\hline & $\mathrm{LH}$ & -0.020 & $0.980(0.921-1.042)$ & 0.419 & 0.518 \\
\hline & FT & 0.011 & $1.011(0.947-1.080)$ & 0.106 & 0.744 \\
\hline & FAl & 0.039 & $1.040(0.983-1.101)$ & 1.842 & 0.175 \\
\hline & SHBG & -0.001 & $0.999(0.988-1.010)$ & 0.039 & 0.884 \\
\hline & $\mathrm{Fl}$ & 0.039 & $1.040(0.995-1.086)$ & 3.054 & 0.081 \\
\hline \multirow[t]{7}{*}{2} & BMI & 0.346 & $1.413(1.259-1.586)$ & 34.408 & 0.000 \\
\hline & Age & 0.125 & $1.134(1.044-1.231)$ & 8.868 & 0.003 \\
\hline & $\mathrm{LH}$ & -0.012 & $0.988(0.927-1.052)$ & 0.146 & 0.702 \\
\hline & $\mathrm{FT}$ & 0.032 & $1.033(0.965-1.105)$ & 0.874 & 0.350 \\
\hline & FAl & 0.045 & $1.046(0.986-1.111)$ & 2.206 & 0.137 \\
\hline & SHBG & -0.001 & $0.999(0.989-1.010)$ & 0.010 & 0.922 \\
\hline & $\mathrm{FI}$ & 0.043 & $1.044(0.996-1.093)$ & 3.234 & 0.072 \\
\hline
\end{tabular}

BMI, body mass index; FT, free testosterone; FAI, free androgen index; SHBG, sex hormone-binding globulin; FI, fasting insulin. All covariables were treated as continous variable. In model 1, only BMI was included; in model 2, both BMI and age were included. 
obese groups. In multivariables logistic regressions, BMI was an independent risk factor for MetS; however, FT, FAI, SHBG, and FI were not included in the formulation by logistic regression analyses, which suggested that BMI is a key factor for developing MetS. Thus, controlling BMI appears to have the most potential in reducing the occurrence of the MetS in women with PCOS.

Age is regarded as an important risk factor for MetS in both general populations and PCOS patients (36-39). In our study, the increasing trend was also found in the prevalence of MetS in two different ways for agegrouping that was consistent with previous reports concerning the relationship between age and MetS in PCOS patients $(11,13)$. Between the two independent risk factors, BMI appeared to contribute more to MetS than age according to the logistic regressions in the present study. This may result from the fact that obesity plays a key role in IR, while IR is one of the most important mechanisms of metablic syndrome.

Although the prevalence of MetS in the present study was lower than that observed in western and some Asian countries, it was still significantly higher than that in healthy counterparts. Since waist circumference values and HDL-C were not available for the controls, the prevalence of MetS could not be calculated according to IDF criteria. We had originally intended to compare our results with an age-matched study on the general population of mainland China based on IDF Criteria; however, no such study was found. As an alternative, we compared our results to a study in Hong Kong (40), in which the prevalence of MetS was $\sim 2$ and $8 \%$ in age groups of $<30$ years and 30-39 years respectively. The prevalence of MetS in PCOS patients aged $<30$ years in our study was almost five times higher than that of their age-matched healthy counterparts; in PCOS patients aged 30-39 years, the prevalence of MetS was over two times higher. This suggests that PCOS patients in China are also at a higher risk of having MetS than those without PCOS, a finding similar to that observed in other countries $(12,13,16,31)$.

The purpose of defining the MetS is to identify those at high risk of CVD and type 2 diabetes. However, documents revealed that the MetS was not superior to the measurement of glucose (fasting or 2-h post load) in identifying those who developed diabetes. Instead, a person with individual components of the MetS can still be associated with high risk of diabetes and CVD in the AusDiab study (41). In our study, we found a low prevalence of the MetS but a high occurrence of individual metabolic disorders in Chinese PCOS patients. Based on the conclusion reached in the AusDiab study, such patients without MetS but with individual components of MetS are at high risk of diabetes and CVDs. Therefore, it is meaningful in clinical practice to detect the various metabolic disorders in PCOS women.

In conclusion, we found a low occurrence of MetS, but high prevalence of the metabolic disorders in the Chinese PCOS patients. The prevalence of MetS increases with BMI and age, the two independent risk factors for predicting MetS, which appeared to contribute more to developing MetS than FT, FAI, FI, or SHBG in this cohort of PCOS patients. So, controlling BMI is not only beneficial to PCOS per se but also important for reducing the long-term detriment of MetS. Since PCOS patients without MetS but with individual components of MetS are also at risk of suffering from diabetes and CVD, it is worthwhile to evaluate the various components of MetS in PCOS patients, particularly in those who are overweight or older than 35 years.

Despite these relevant findings, it is important to point out the limitations of our study. Waist circumference measurements and HDL-C level were unavailable in the controls; therefore, the prevalence of MetS in women with PCOS could not be compared with that in controls from the same region. We look forward to evaluating this issue in a future paper. In addition, selection biases may have existed, since only those who had complete medical records were selected for inclusion in the study.

\section{Declaration of interest}

Authors have no possible conflict of interest to disclose.

\section{Funding}

This study was supported by grants from Chinese Key Projects in the National Science Technology Pillar Program in the Eleventh Five-year Plan Period (Grant No. 2007BA104B00), the Medical Science Research Foundation of Guangdong Province (Grant No. B2007053).

\section{Author contribution statement}

Each of us acknowledges that he or she participated sufficiently in the work.

\section{References}

1 Alberti KG, Zimmet P \& Shaw J. IDF Epidemiology Task Force Consensus Group. The metabolic syndrome - a new worldwide definition. Lancet 2005366 1059-1062.

2 Alberti KG, Zimmet P \& Shaw J. Metabolic syndrome - a new world-wide definition. A Consensus Statement from the International Diabetes Federation. Diabetic Medicine 2006 23 469-480.

3 Stoll BA. Western nutrition and the insulin resistance syndrome: a link to breast cancer. European Journal of Clinical Nutrition 1999 53 83-87.

4 Lahmann PH, Hoffmann K, Allen N, van Gils CH, Khaw KT, Tehard B, Berrino F, Tjønneland A, Bigaard J, Olsen A, Overvad K, Clavel-Chapelon F, Nagel G, Boeing H, Trichopoulos D, Economou G, Bellos G, Palli D, Tumino R, Panico S, Sacerdote C, Krogh V, Peeters PH, Bueno-de-Mesquita HB, Lund E, Ardanaz E, Amiano P, Pera G, Quirós JR, Martínez C, Tormo MJ, Wirfält E, Berglund G, Hallmans G, Key TJ, Reeves G, Bingham S, Norat T, Biessy C, Kaaks R \& Riboli E. Body size and breast cancer risk: findings from the European Prospective Investigation into Cancer and Nutrition (EPIC). International Journal of Cancer 2004111 762-771.

5 Pischon T, Lahmann PH, Boeing H, Friedenreich C, Norat T, Tjønneland A, Halkjaer J, Overvad K, Clavel-Chapelon F, 
Boutron-Ruault MC, Guernec G, Bergmann MM, Linseisen J, Becker N, Trichopoulou A, Trichopoulos D, Sieri S, Palli D, Tumino R, Vineis P, Panico S, Peeters PH, Bueno-de-Mesquita HB, Boshuizen HC, Van Guelpen B, Palmqvist R, Berglund G, Gonzalez CA, Dorronsoro M, Barricarte A, Navarro C, Martinez C, Quirós JR, Roddam A, Allen N, Bingham S, Khaw KT, Ferrari P, Kaaks R, Slimani N \& Riboli E. Body size and risk of colon and rectal cancer in the European Prospective Investigation into Cancer and Nutrition (EPIC). Journal of the National Cancer Institute 200698 920-931.

6 Diamanti-Kandarakis E, Kouli CR, Bergiele AT, Filandra FA, Tsianateli TC, Spina GG, Zapanti ED \& Bartzis MI. A survey of the polycystic ovary syndrome in the Greek island of Lesbos: hormonal and metabolic profile. Journal of Clinical Endocrinology and Metabolism 199984 4006-4011.

7 Dunaif A \& Thomas A. Current concepts in the polycystic ovary syndrome. Annual Review of Medicine 200152 401-419.

8 Asunción M, Calvo RM, San Millán JL, Sancho J, Avila S \& EscobarMorreale HF. A prospective study of the prevalence of the polycystic ovary syndrome in unselected Caucasian women from Spain. Journal of Clinical Endocrinology and Metabolism 200085 2434-2438.

9 Legro RS, Kunselman AR \& Dunaif A. Prevalence and predictors of dyslipidemia in women with polycystic ovary syndrome. American Journal of Medicine 2001111 607-613.

10 Coviello AD, Legro RS \& Dunaif A. Adolescent girls with polycystic ovary syndrome have an increased risk of the metabolic syndrome associated with increasing androgen levels independent of obesity and insulin resistance. Journal of Clinical Endocrinology and Metabolism 200691 492-497.

11 Glueck CJ, Papanna R, Wang PN \& Sieve-Smith L. Incidence and treatment of metabolic syndrome in newly referred women with confirmed polycystic ovarian syndrome. Metabolism 200352 908-915.

12 Dokras A, Bochner M, Hollinrake E, Markham S, Vanvoorhis B \& Jagasia DH. Screening women with polycystic ovary syndrome for metabolic syndrome. Obstetrics and Gynecology 2005106 131-137.

13 Apridonidze T, Essah PA, Iuorno MJ \& Nestler JE. Prevalence and characteristics of the metabolic syndrome in women with polycystic ovary syndrome. Journal of Clinical Endocrinology and Metabolism 200590 1929-1935.

14 Bhattacharya SM. Metabolic syndrome in females with polycystic ovary syndrome and International Diabetes Federation criteria. Journal of Obstetrics and Gynaecology Research 2008 34 62-66.

15 Soares EM, Azevedo GD, Gadelha RG, Lemos TM \& Maranhão TM. Prevalence of the metabolic syndrome and its components in Brazilian women with polycystic ovary syndrome. Fertility and Sterility $2008 \mathbf{8 9} 649-655$.

16 Park HR, Choi Y, Lee HJ, Oh JY, Hong YS \& Sung YA. The metabolic syndrome in young Korean women with polycystic ovary syndrome. Diabetes Research and Clinical Practice $2007 \mathbf{7 7}$ S243-S246.

17 Weerakiet S, Bunnag P, Phakdeekitcharoen B, Wansumrith S, Chanprasertyothin S, Jultanmas R \& Thakkinstian A. Prevalence of the metabolic syndrome in Asian women with polycystic ovary syndrome: using the International Diabetes Federation criteria. Gynecological Endocrinology 200723 153-160.

18 Chen X, Yang D, Mo Y, Li L, Chen Y \& Huang Y. Prevalence of polycystic ovary syndrome in unselected women from Southern China. European Journal of Obstetrics, Gynecology, and Reproductive Biology 2008139 59-64.

19 Rotterdam ESHRE/ASRM-Sponsored PCOS Consensus Workshop Group. Revised 2003 consensus on diagnostic criteria and long-term health risks related to polycystic ovary syndrome. Fertility and Sterility 200481 19-25.

20 Azziz R, Woods KS, Reyna R, Key TJ, Knochenhauer ES \& Yildiz BO. The prevalence and features of the polycystic ovary syndrome in an unselected population. Journal of Clinical Endocrinology and Metabolism 200489 2745-2749.
21 Hatch R, Rosenfield RL, Kim MH \& Tredway D. Hirsutism: implications, etiology, and management. American Journal of Obstetrics and Gynaecology $1981 \mathbf{1 4 0} 815-830$.

22 International Diabetes Federation (2005) The IDF consensus worldwide definition of the metabolic syndrome. Available from http://www.idf.org/webdata/docs/Metabolic_syndrome_de finition.pdf. Accessed 10 July 2008.

23 World Health Organization. Measuring Obesity: Classification and Distribution of Anthropometric Data. Copenhagen: WHO, 1989 (Nutr UD, EUR/ICP/NUT 125).

24 The World Health Organization Western Pacific Region, the International Association for the Study of Obesity, and the International Obesity Task Force. The Asia-Pacific Perspective: Redefining Obesity and its Treatment. Melbourne: Health Communications Australia, 2000.

25 Mathur RS, Moody LO, Landgrebbe S \& Williamson HO. Plasma androgens and sex hormone binding globulin in the evaluation of hirsute patients. Fertility and Sterility 198135 29-37.

26 Matthews DR, Hosker JP, Rudenski AS, Naylor BA, Treacher DF \& Turner RC. Homeostasis model assessment: insulin resistance and B-cell function from fasting plasma glucose and insulin concentrations in man. Diabetologia 198528 412-419.

27 Cussons AJ, Watts GF, Burke V, Shaw JE, Zimmet PZ \& Stuckey BG. Cardiometabolic risk in polycystic ovary syndrome: a comparison of different approaches to defining the metabolic syndrome. Human Reproduction 200823 2352-2358.

28 Tan CE, Ma S, Wai D, Chew SK \& Tai ES. Can we apply the National Cholesterol Education Program Adult Treatment Panel definition of the metabolic syndrome to Asians? Diabetes Care 200427 $1182-1186$.

29 Zhu S, St-Onge MP, Heshka S \& Heymsfield SB. Lifestyle behaviors associated with lower risk of having the metabolic syndrome. Metabolism 200453 1503-1511.

30 Carmina E, Legro RS, Stamets K, Jowell J \& Lobo RA. Difference in body weight between American and Italian women with polycystic ovary syndrome: influence of the diet. Human Reproduction 200318 2289-2293.

31 Hahn S, Tan S, Sack S, Kimmig R, Quadbeck B, Mann K \& Janssen OE. Prevalence of metabolic syndrome in German women with polycystic ovary syndrome. Experimental and Clinical Endocrinology and Diabetes 2007115 130-135.

32 Chen MJ, Yang WS, Yang JH, Hsiao CK, Yang YS \& Ho HN. Low sex hormone-binding globulin is associated with low high-density lipoprotein cholesterol and metabolic syndrome in women with PCOS. Human Reproduction 200621 2266-2271.

33 Lo JC, Feigenbaum SL, Yang J, Pressman AR, Selby JV \& Go AS. Epidemiology and adverse cardiovascular risk profile of diagnosed polycystic ovary syndrome. Journal of Clinical Endocrinology and Metabolism 200691 1357-1363.

34 Carmina E, Napoli N, Longo RA, Rini GB \& Lobo RA. Metabolic syndrome in polycystic ovary syndrome (PCOS): lower prevalence in Southern Italy than in the USA and the influence of criteria for the diagnosis of PCOS. European Journal of Endocrinology 2006 154 141-145.

35 Li L, Yang D, Chen X, Chen Y, Feng S \& Wang L. Clinical and metabolic features of polycystic ovary syndrome. International Journal of Gynaecology and Obstetrics 200797 129-134.

36 Li ZY, Xu GB \& Xia TA. Prevalence rate of metabolic syndrome and dyslipidemia in a large professional population in Beijing. Atherosclerosis $2006 \mathbf{1 8 4} 188-192$.

37 Park YW, Zhu S, Palaniappan L, Heshka S, Carnethon MR \& Heymsfield SB. The metabolic syndrome: prevalence and associated risk factor findings in the US population from the Third National Health and Nutrition Examination Survey, 1988-1994. Archives of Internal Medicine 2003163 427-436.

38 Miccoli R, Bianchi C, Odoguardi L, Penno G, Caricato F, Giovannitti MG, Pucci L \& Del Prato S. Prevalence of the metabolic syndrome among Italian adults according to ATP III definition. Nutrition, Metabolism, and Cardiovascular Diseases 200515 $250-254$. 
39 Hildrum B, Mykletun A, Hole T, Midthjell K \& Dahl AA. Agespecific prevalence of the metabolic syndrome defined by the International Diabetes Federation and the National Cholesterol Education Program: the Norwegian HUNT 2 study. BMC Public Health 20077 220-228.

40 Ko GTC \& Tang JSF. Metabolic syndrome in the Hong Kong community: the United Christian Nethersole Community Health Service primary healthcare programme 2001-2002. Singapore Medical Journal 200748 1111-1116.
41 Cameron AJ, Magliano DJ, Zimmet PZ, Welborn TA, Colagiuri S, Tonkin AM \& Shaw JE. The metabolic syndrome as a tool for predicting future diabetes: the AusDiab study. Journal of Internal Medicine 2008264 177-186.

Received 14 June 2009

Accepted 19 June 2009 